\title{
HONORÁRIOS NA JUSTIÇA DO TRABALHO E NO PROCESSO CIVIL E O (NÃO) EXERCÍCIO DO PRINCÍPIO FUNDAMENTAL DA CIDADANIA
}

\section{LUCIANO EHLKE RODRIGUES}

Tem vasta experiência na área de Direito. Atuação prática há 18 anos, com ênfase em Direito e Processo do Trabalho.

\section{RESUMO}

O objetivo do presente estudo é analisar como vem se comportando a questão da fixação dos honorários de sucumbência na Justiça do trabalho e no Processo Civil. Para tanto, abordaremos a temática sob a ótica do Novo Código de Processo Civil bem como no espectro da Lei 13.467/2017, enfrentando os artigos específicos que versam sobre o assunto. O pano de fundo sobre o qual haverá a análise dos dispositivos legais afeitos ao tema, bem como a doutrina e a jurisprudência vem se posicionando acerca da aplicabilidade dos honorários de sucumbência, tanto no campo do direito civil, quanto no da Justiça do trabalho. Ao fim, será abordado de que forma tais dispositivos legais tem influenciado tais ramos do Direito na perspectiva da Constituição da república Federativa do Brasil, em especial sobre o princípio fundamental da Cidadania.

PALAVRAS-CHAVE: Cidadania; Honorários Sucumbenciais; Constituição Federal.

\section{METODOLOGIA}

A metodologia eleita para tal mister é a análise dos dispositivos legais afeitos ao tema dos honorários de sucumbência, bem como a visão doutrinária a 


\section{Personalidade Acadêmica Homenageada: Florisbal de Souza Del'Olmo (Professor Convidado - UNICURITIBA)}

respeito de tal temática, sem deixar de lado o contraponto forjado na Constituição Federal.

Tomando-se por base a Constituição Federal de 1988, promulgada em 5 de outubro de 1988, bem como na análise do art. 85 , da Lei n.․ $13.105 / 2015^{1}$ e da Lei $13.467 / 2017$, procuraremos abordar como tais leis influenciam nos aspectos econômicos e sociais dos jurisdicionados. ${ }^{2}$

\footnotetext{
${ }^{1}$ Com vigência a partir de 18-3-2016, por decisão do Pleno do Superior Tribunal de Justiça. Para maiores informações, pode ser acessado o site: CONSULTOR JURÍDICO, 2016.

${ }^{2}$ Art. 85. A sentença condenará o vencido a pagar honorários ao advogado do vencedor. $\S 1^{\circ}$ São devidos honorários advocatícios na reconvenção, no cumprimento de sentença, provisório ou definitivo, na execução, resistida ou não, e nos recursos interpostos, cumulativamente. $\S 2^{\circ}$ Os honorários serão fixados entre o mínimo de dez e o máximo de vinte por cento sobre o valor da condenação, do proveito econômico obtido ou, não sendo possível mensurá-lo, sobre o valor atualizado da causa, atendidos: I - o grau de zelo do profissional; II - o lugar de prestação do serviço; III - a natureza e a importância da causa; IV - o trabalho realizado pelo advogado e o tempo exigido para o seu serviço. $\S 3^{\circ}$ Nas causas em que a Fazenda Pública for parte, a fixação dos honorários observará os critérios estabelecidos nos incisos I a IV do $\S 2^{\circ}$ e os seguintes percentuais: I - mínimo de dez e máximo de vinte por cento sobre o valor da condenação ou do proveito econômico obtido até 200 (duzentos) salários-mínimos; II - mínimo de oito e máximo de dez por cento sobre o valor da condenação ou do proveito econômico obtido acima de 200 (duzentos) salários-mínimos até 2.000 (dois mil) salários-mínimos; III - mínimo de cinco e máximo de oito por cento sobre o valor da condenação ou do proveito econômico obtido acima de 2.000 (dois mil) salários-mínimos até 20.000 (vinte mil) salários-mínimos; IV - mínimo de três e máximo de cinco por cento sobre o valor da condenação ou do proveito econômico obtido acima de 20.000 (vinte mil) salários-mínimos até 100.000 (cem mil) salários-mínimos; V - mínimo de um e máximo de três por cento sobre o valor da condenação ou do proveito econômico obtido acima de 100.000 (cem mil) salários-mínimos. $\S 4^{\circ} \mathrm{Em}$ qualquer das hipóteses do $\S 3^{\circ}$ : I - os percentuais previstos nos incisos I a V devem ser aplicados desde logo, quando for líquida a sentença; II - não sendo líquida a sentença, a definição do percentual, nos termos previstos nos incisos I a V, somente ocorrerá quando liquidado o julgado; III não havendo condenação principal ou não sendo possível mensurar o proveito econômico obtido, a condenação em honorários dar-se-á sobre o valor atualizado da causa; IV - será considerado o salário-mínimo vigente quando prolatada sentença líquida ou o que estiver em vigor na data da decisão de liquidação. $\S 5^{\circ}$ Quando, conforme o caso, a condenação contra a Fazenda Pública ou o benefício econômico obtido pelo vencedor ou o valor da causa for superior ao valor previsto no inciso I do $\S 3^{\circ}$, a fixação do percentual de honorários deve observar a faixa inicial e, naquilo que a exceder, a faixa subsequente, e assim sucessivamente. $\S 6^{\circ}$ Os limites e critérios previstos nos $\S \S 2^{\circ} \mathrm{e}$ $3^{\circ}$ aplicam-se independentemente de qual seja o conteúdo da decisão, inclusive aos casos de improcedência ou de sentença sem resolução de mérito. $\S 7^{\circ}$ Não serão devidos honorários no cumprimento de sentença contra a Fazenda Pública que enseje expedição de precatório, desde que não tenha sido impugnada. $\S 8^{\circ}$ Nas causas em que for inestimável ou irrisório o proveito econômico ou, ainda, quando o valor da causa for muito baixo, o juiz fixará o valor dos honorários por apreciação equitativa, observando o disposto nos incisos do $\S 2^{\circ}$. $\S 9^{\circ} \mathrm{Na}$ ação de indenização por ato ilícito contra pessoa, o percentual de honorários incidirá sobre a soma das prestações vencidas acrescida de 12 (doze) prestações vincendas. § 10. Nos casos de perda do objeto, os honorários serão devidos por quem deu causa ao processo. § 11. O tribunal, ao julgar recurso, majorará os honorários fixados anteriormente levando em conta o trabalho adicional realizado em grau recursal, observando, conforme o caso, o disposto nos $\S \S 2^{\circ}$ a $6^{\circ}$, sendo vedado ao tribunal, no cômputo geral da fixação de honorários devidos ao advogado do vencedor, ultrapassar os respectivos limites estabelecidos nos $\S \S$ $2^{\circ}$ e $3^{\circ}$ para a fase de conhecimento. $\S 12$. Os honorários referidos no $\S 11$ são cumuláveis com
} 


\section{Personalidade Acadêmica Homenageada: \\ Florisbal de Souza Del'Olmo (Professor Convidado - UNICURITIBA)}

Se, no âmbito do Processo Civil, já existia uma maior acomodação quanto ao tema sob enfoque, no que pertinente aos honorários sucumbenciais, o mesmo não pode se dizer nos meandros da Justiça Especializada Laboral. O tempo de maturação que foi fixado, mais conhecido como "vacacio legis", para o Novo Processo Civil foi de um ano, enquanto que, para a Lei 13.467/2017, entendeu o legislador em fixar um tempo de vigência menor, qual seja de 120 dias.

Com isso, o Código de Processo Civil de 2015, com as mudanças que advieram no campo dos honorários de sucumbência, foram absorvidas pelos entes sociais por um maior tempo do que na Justiça do Trabalho, exigindo, por esse modo, da doutrina especializada no ramo do direito do trabalho, que se produzissem estudos avançados acerca do novel diploma laboral, qual seja, da Lei 13.467/2017, até mesmo em razão das inúmeras mudanças advindas.

Dallegrave Neto, ao tratar do tema, é enfático ao tratar da aplicação da Lei nova (Lei 13.467/2017) sobre processos antigos, afirma que:

[...] Com efeito, haverá regras processuais novas que se aplicarão desde logo aos processos em curso, a exemplo da contagem em dias úteis, introduzida pelo art. 775 da CLT, a partir da Lei n. .0 13.467/2017. Outras regras heterotópicas, como os honorários de sucumbência recíproca, previstos no art. $791-\mathrm{A}, \S^{\circ}$, da $\mathrm{CLT}$, somente incidirão sobre as ações ajuizadas a partir da vigência da nova lei, uma vez que se reportam aos atos processuais complexos, com efeitos diferidos e além da órbita processual [...].

A regra nova dos honorários no Código de Processo Civil, procurou dinamizar e esmiuçar as hipóteses de aplicação de tal instituto, porquanto deixava

multas e outras sanções processuais, inclusive as previstas no art. 77 . $\S 13$. As verbas de sucumbência arbitradas em embargos à execução rejeitados ou julgados improcedentes e em fase de cumprimento de sentença serão acrescidas no valor do débito principal, para todos os efeitos legais. $\S 14$. Os honorários constituem direito do advogado e têm natureza alimentar, com os mesmos privilégios dos créditos oriundos da legislação do trabalho, sendo vedada a compensação em caso de sucumbência parcial. $\S 15$. O advogado pode requerer que o pagamento dos honorários que the caibam seja efetuado em favor da sociedade de advogados que integra na qualidade de sócio, aplicando-se à hipótese o disposto no $\S 14$. $\S 16$. Quando os honorários forem fixados em quantia certa, os juros moratórios incidirão a partir da data do trânsito em julgado da decisão. $\S 17$. Os honorários serão devidos quando o advogado atuar em causa própria. § 18. Caso a decisão transitada em julgado seja omissa quanto ao direito aos honorários ou ao seu valor, é cabível ação autônoma para sua definição e cobrança. § 19. Os advogados públicos perceberão honorários de sucumbência, nos termos da lei. 


\section{Personalidade Acadêmica Homenageada: \\ Florisbal de Souza Del'OImo (Professor Convidado - UNICURITIBA)}

ao alvedrio do magistrado a equalização da fixação e dos critérios a serem adotados, até mesmo em razão da gama maior de hipóteses de causas submetidas ao Processo Civil. Por outro norte, a recente mudança introduzida pela Lei $\mathrm{n} .^{\circ}$ 13.467/2017, que introduziu no microcosmos do Direito do Trabalho, a redação do art. 791- $\mathrm{A}^{3}$, da Consolidação das Leis do trabalho, trouxe consigo, impactos no campo econômico e social tanto para o empregador quanto para o Empregado. A própria escolha dos pedidos e sua possibilidade ou não de êxito passa ser a tônica para a propositura ou não das demandas trabalhistas.

Por outro lado, mostra-se extremamente relevante perquirir-se na doutrina, até que ponto o potencial risco de condenação afetaria ou não o exercício da cidadania por parte dos jurisdicionados que buscam o Judiciário Trabalhista, enquanto princípio fundamental da Constituição da República Federativa do Brasil, conforme disposto no art. $1^{\circ}$, II, que consagra tal princípio.

\section{REVISÃO DE LITERATURA}

Importantes estudos, tanto no campo do Processo Civil, como no do Direito Processual do Trabalho, muito tem contribuído para a tarefa do judiciário em fixar critérios para os honorários de sucumbência. Ao longo desse breve resumo, pudemos verificar as alternativas que a doutrina literária especializada tem

\footnotetext{
3 "Art. 791-A. Ao advogado, ainda que atue em causa própria, serão devidos honorários de sucumbência, fixados entre o mínimo de 5\% (cinco por cento) e o máximo de 15\% (quinze por cento) sobre o valor que resultar da liquidação da sentença, do proveito econômico obtido ou, não sendo possível mensurá-lo, sobre o valor atualizado da causa. $\S 1^{\circ}$ Os honorários são devidos também nas ações contra a Fazenda Pública e nas ações em que a parte estiver assistida ou substituída pelo sindicato de sua categoria. $\S 2^{\circ}$ Ao fixar os honorários, o juízo observará: I - o grau de zelo do profissional; II - o lugar de prestação do serviço; III - a natureza e a importância da causa; IV - o trabalho realizado pelo advogado e o tempo exigido para o seu serviço. $\S 3^{\circ} \mathrm{Na}$ hipótese de procedência parcial, o juízo arbitrará honorários de sucumbência recíproca, vedada a compensação entre os honorários. $\S 4^{\circ}$ Vencido o beneficiário da justiça gratuita, desde que não tenha obtido em juízo, ainda que em outro processo, créditos capazes de suportar a despesa, as obrigações decorrentes de sua sucumbência ficarão sob condição suspensiva de exigibilidade e somente poderão ser executadas se, nos dois anos subsequentes ao trânsito em julgado da decisão que as certificou, o credor demonstrar que deixou de existir a situação de insuficiência de recursos que justificou a concessão de gratuidade, extinguindo-se, passado esse prazo, tais obrigações do beneficiário. $\S 5^{\circ}$ São devidos honorários de sucumbência na reconvenção."
} 
Personalidade Acadêmica Homenageada:

Florisbal de Souza Del'Olmo (Professor Convidado - UNICURITIBA)

apontado, para equacionar o tema, o que poderá ser ampliado ao longo do cronograma de estudos que serão realizados sob este viés.

\section{CONCLUSÃO}

Em concluimento, é imperioso que se busque atingir um contraponto entre a aplicação dos honorários na Justiça do trabalho, utilizando-se das experiências albergadas no âmbito do Processo Civil, de modo a não violar o exercício da Cidadania, guindado a princípio Fundamental da Constituição Federal de 1988.

\section{REFERÊNCIAS}

BRASIL. Constituição (1988). Constituição da República Federativa do Brasil. Disponível em: $\quad$ https://www.inss.gov.br/servicos-do-inss/calculo-da-guia-daprevidencia-social-gps/tabela-de-contribuicao-mensal/>. Acesso em 03/10/2018.

Lei № 13.105, de 16 de Março de 2015 http://www.planalto.gov.br/ccivil 03/ ato2015-2018/2015/lei//13105.htm Acesso em 20-10-2018.

Lei № 13.467, de 13 de Julho de 2017. http://www.planalto.gov.br/ccivil 03/ ato2015-2018/2017/lei//13467.htm Acesso em 20-10-2018.

CANOTILHO, José Joaquim Gomes. Direito Constitucional e teoria da Constituição. 7. Ed. Coimbra: Almedina, 2000.

CONSULTOR JURÍDICO. Novo CPC entrará em vigor no dia 18 de março, define Plenário do STJ. 2016. Disponível em: https://www.conjur.com.br/2016-mar-02/cpcentrara-vigor-dia-18-marco-define-stj. Acesso em 20.nov.2018.

DIDIER JR, Fredie. Curso de direito processual civil. 17. Ed. Salvador: Juspodivm, 2015.

MARTINEZ, LUCIANO. et al. A Reforma trabalhista na visão da Academia Brasileira de Direito do Trabalho. Porto Alegre: Lex Magister, 2018.

SCHIAVI, Mauro. Manual de direito processual do trabalho. 12. Ed. São Paulo: LTr, 2017. 
Personalidade Acadêmica Homenageada:

Florisbal de Souza Del'Olmo (Professor Convidado - UNICURITIBA)

SOUZA JÚNIOR, A. et al. Reforma Trabalhista. Análise Comparativa e crítica da Lei n.o 13.467/2017 e da Med. Prov. N.․ 808/2017. São Paulo: Rideel, 2018.

SILVA, Homero B. M. Comentários à Reforma Trabalhista. Análise da Lei 13.467/2017. Artigo por artigo. 2ª Edição: Revista e Ampliada. São Paulo: Revista dos Tribunais, 2017. 